\title{
Comparison of Health Literacy of the Population Regarding Healthy Diet and Chronic Liver Diseases - \\ West vs. East of Slovakia
}

I. Klobusovska (Ivana Klobusovska) $)^{1}$, M. Belovicova (Maria Belovicova)2,3,4,

V. Ivankova (Viera Ivankova)5,6, M. Popovicova (Maria Popovicova)²,

T. Hudakova (Tatiana Hudakova) $)^{5,7}$

${ }^{1}$ Regional Public Health Authority with the seat in Bardejov, SK.

Original Article

${ }^{2}$ St. Elizabeth University of Health and Social Sciences,

Bratislava - Teacher, SK.

${ }^{3}$ Internal Clinic for Liver Disease Diagnosis and Treatment, Remedium s.r.o., SK.

${ }^{4}$ Slovak Society of Practical Obesitology (SSPO), Bardejov, SK.

${ }^{5}$ St. Elizabeth University of Health and Social Sciences, Bratislava - student of external doctoral study, SK.

${ }^{6}$ Hospital and Health Care Centre of S. Kukura (NsP S. Kukuru), Michalovce, SK.

${ }^{7}$ Hospital and Health Care Centre Trebisov (NsP Trebisov), World of Health, SK.

\section{E-mail address:}

bj.klobusovska@uvzsr.sk

\section{Reprint address:}

Regional Public Health Authority with the seat in Bardejov

Kuzmanyho 18

08567 Bardejov

Slovakia

Source: Clinical Social Work and Health Intervention

Volume: 12

Issue: 5

Pages: $22-28$

Cited references: 13

\section{Reviewers:}

Gabriela Lezcano

University of California, San Francisco, USA

Steve Szydlowski

University of Scranton school of education, USA

\section{Keywords:}

Population Health Literacy. Chronic Diseases. Healthy Diet. Education. Nursing. Public Health.

\section{Publisher:}

International Society of Applied Preventive Medicine i-gap

CSWHI 2021; 12(5): 22 - 28; DOI: 10.22359/cswhi_12_5_03 (C) Clinical Social Work and Health Intervention

\section{Abstract:}

Introduction: The health status of the population is a result of the complex action of several components of society. Chronic non-communicable diseases are the leading cause of death. They are often a result of smoking, alcohol consumption, poor diet and lack of exercise. 
Objectives: To obtain and compare information on health literacy of the population (Western versus Eastern Slovakia) regarding the most common liver diseases, risk factors for chronic liver diseases and healthy diet.

Research sample group and methodology: A self-designed questionnaire was composed of 30 questions. 400 respondents helped us to carry out the research: 145 men and 255 women. 200 respondents came from Western Slovakia and 200 respondents from Eastern Slovakia.

Results: We established several hypotheses, based on which we determined health literacy of the population in Eastern and Western Slovakia. Health literacy is statistically significantly higher in a selected sample of respondents from the western part of Slovakia.

Conclusions: In order to improve the health of the population, it is necessary to pay great attention to the education of the population about chronic diseases and healthy diet by all, the public health authorities, medicine and nursing. Close cooperation with general practitioners is a basic prerequisite for the successful solving of this problem.

\section{Introduction}

Many different internal and external factors contribute to our health - genetic predispositions, psychological factors, stress, nutrition, degree of physical fitness, but also the availability and organization of healthcare. The state of our health is also affected by other factors such as education, economy, culture, safety, housing, technologies, habits, but also individual behavior in relation to one's health. The health status of the population is a result of the complex action of several components of society (1).

In Europe, up to 29 million people suffer from some kind of liver diseases, which most often affect people of working age. Chronic diseases are the leading cause of death and of poor quality of life in Europe. More than 4 million people in the EU die from chronic diseases every year. Worldwide, each year, 39.5 million people die from chronic diseases. If the current status is maintained, the number of deaths caused by chronic diseases will increase to 55 million by $2030(2,3)$.

Chronic non-communicable diseases are the leading cause of death. Here we include: cardiovascular diseases; cancer (digestive tract, esophagus, stomach, liver, colon, rectum, breast, prostate, lungs, bladder, uterus, nervous system and blood cancer); chronic respiratory diseases; metabolic diseases (e.g. diabetes mellitus, metabolic syndrome and others), mental disorders and psychiatric diseases, injuries and others (1). Chronic diseases also represent an economic burden for the state as people in the bloom of life lose the ability to work. Many chronic diseases are preventable. They are often a result of smoking, alcohol consumption, poor diet and lack of exercise (4).

The Mediterranean diet is considered a model of a healthy diet. According to a study in the British Medical Journal from 2009, some components of the Mediterranean Diet, such as high consumption of vegetables and low consumption of meat and meat products, correlate with a lower risk of mortality more than other components, such as consumption of fish and cereals. Moderate alcohol consumption, high consumption of fruit, nuts and legumes also accompany a lower risk of mortality (5).

Education has long been one of the most important determinants of health. Investing in education is investing in health. The more pupils continue their education at a secondary school and finish it with a school leaving examination, the better the chances of a healthier population (6). 


\section{Research objective}

To obtain information on health literacy of the population regarding the most common liver diseases; risk factors for chronic liver diseases; healthy diet. We compare the health awareness of chronic liver diseases in the western and the eastern part of Slovakia.

\section{Research sample group and methodology}

A self-designed questionnaire was composed of 30 questions concerning demographic and identification data and data relating to knowledge of liver diseases. 400 respondents helped us to carry out the research: 145 men and 255 women. 200 respondents came from Western Slovakia and 200 respondents from Eastern Slovakia. Our goal was to obtain information about health literacy of the population. All respondents were informed about anonymity. A total of 400 questionnaires were distributed, all of which were returned to us, which meant $100 \%$ return rate. The target group of respondents were patients from outpatient clinics from Eastern and Western Slovakia (Policlinic SZU - Kramare, Poliklinika Remedium Bardejov Spa). The first 6 items of the questionnaire dealt with data such as: age, gender, height, weight, completed education and residence. Regarding the age structure, the largest group of respondents was the age category up to 50 years. The least represented was the age category 81 years and over. Another item concerned gender. Of the 400 respondents, 145 were men and 255 were women. We also examined the highest level of education attained. Most respondents $(43.3 \%)$ had completed secondary school with a school leaving examination and the least $(5.3 \%)$ had completed elementary school.

Results: We set several hypotheses based on which we determined health literacy of the population in Eastern and Western Slovakia. For the needs of this publication, we have selected only some of the hypotheses.

Hypothesis 1: We assume that in Eastern Slovakia health literacy of the population about chronic liver diseases is significantly lower than in the Western part of the Slovak Republic.

Hypothesis 2: We assume that respondents with higher education go to preventive check-ups more regularly than people with lower education.

Hypothesis 3: We assume that in Eastern
Slovakia there is a lower health awareness of the population regarding healthy diet than in the western part of the Slovak Republic.

We tested Hypothesis 1 using Mann Whitney's test. Questions 7-15 concerned the knowledge about non-alcoholic fatty liver disease; its risk factors; the possibility of transmitting chronic viral hepatitis, the meaning of elevated liver function tests.

Conclusion: Health awareness is statistically significantly higher in a selected sample of respondents from Western Slovakia.

The questions in the questionnaire related to Hypothesis 2 were numbered 16-21. We show the results of Hypothesis $\mathbf{2}$ in graph 1 .

In Graph 1 we can see that the preventive check-ups are attended regularly by 19 respondents with elementary education; 47 respondents with secondary school without a school leaving examination; 125 respondents with secondary school with a school leaving examination; 96 respondents with a university degree. We also see that preventive check-ups do not attend: 2 respondents with elementary education; 27 with secondary school without a school leaving examination; 48 with secondary school with a school leaving examination; 36 respondents with a university degree.

Conclusion: Hypothesis 2 was confirmed only in question 21 , which concerned participation in preventive examinations, participation was significantly higher in respondents with higher education $(p=0.013)$. The hypothesis was not confirmed in the questions of monitoring the health status (measuring and knowing the values of one's own blood pressure, knowing the values of cholesterol and glycaemia). Differences in the care of one's health do not depend on education.

In Hypothesis 3, we assumed that in Eastern Slovakia there is a lower health awareness of the population regarding healthy diet than in Western Slovak Republic. Questions 22-27 concerned the frequency of eating; the consumption of vegetables; most frequently consumed healthy foods; the frequency of consumption of meat products and fish.

Conclusion: Hypothesis 3 was confirmed only in 3 Questions (22 - frequency of eating; 26 - frequency of consumption of meat and meat products; 27 - frequency of consumption of fish). Nevertheless, we state that the health awareness 
of a healthy diet is higher in Western regions of the Slovak Republic.

\section{Discussion}

In Slovakia, chronic liver diseases are the $5^{\text {th }}$ most common cause of death and in the case of productive age they take 3rd place right after cardiovascular and oncological diseases. In 2014, chronic liver diseases caused $4 \%$ of deaths in men and 2\% in women. The European Association for the Study of the Liver rates Slovakia as the country with the 4th highest mortality from liver diseases (4). We tried to compare the situa- tion of health literacy about chronic liver diseases in Western and Eastern Slovakia. Factors such as gender, age, residence and completed education were evaluated and assigned to the level of knowledge and opinion about liver diseases.

In the first hypothesis, we assumed that in Eastern Slovakia there is a significantly lower health awareness of the population about chronic liver diseases than in Western Slovakia. We verified the hypothesis with Questions 7-15, using the Mann Whitney test. In Question 14 we asked respondents if they know how a person could get infected with Hepatitis B or C: The possibility of

Graph 1 Do you go to regular preventive check-ups?

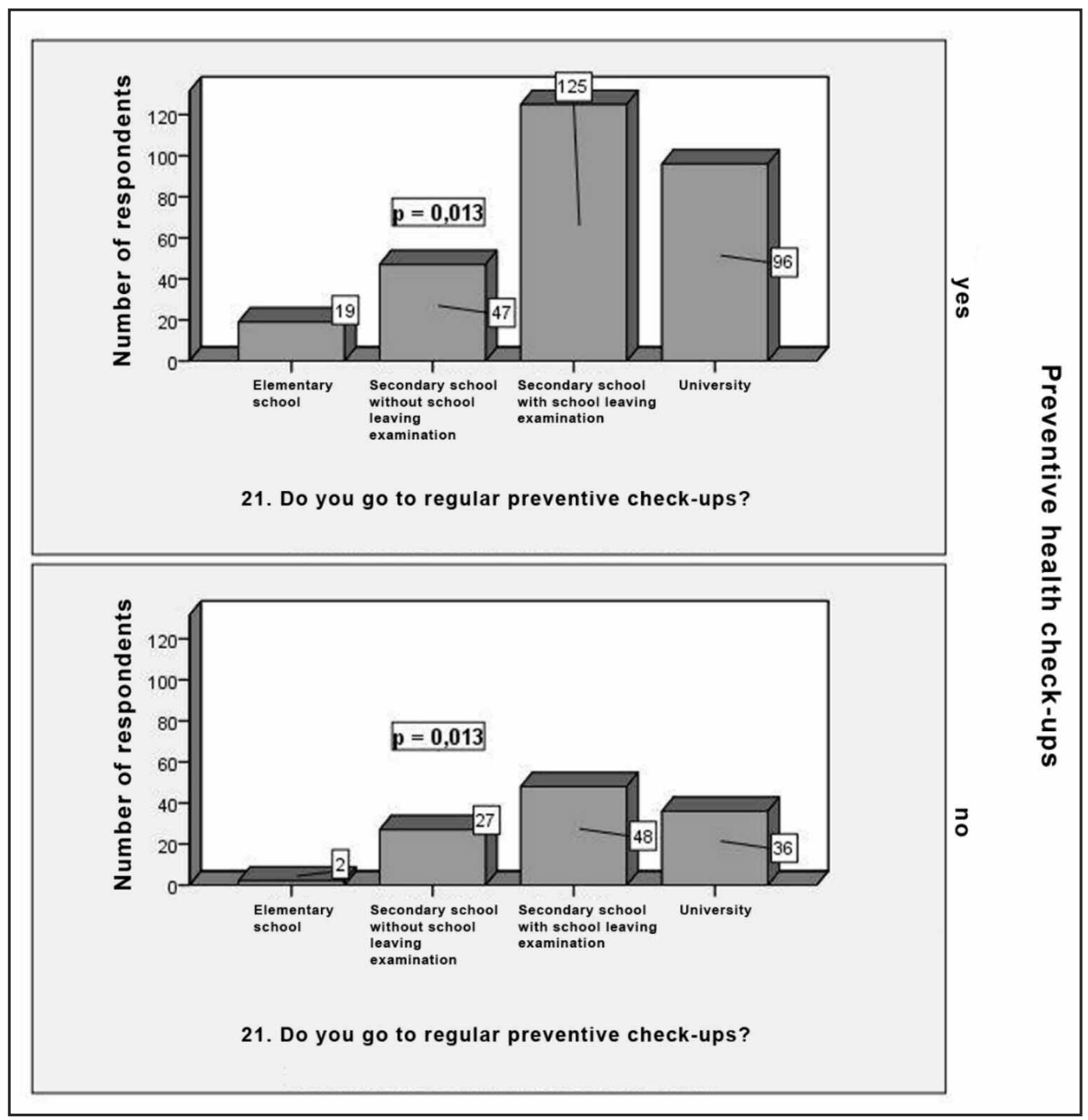


sexual intercourse was reported by $10.8 \%$ of the respondents; by intravenous drug use by $10.5 \%$ of the respondents; $8.3 \%$ think that with blood; $4.0 \%$ answered with tattoos and piercings; $66.5 \%$ of respondents could not give an answer and answered "do not know".

Conclusion: Health awareness of chronic liver diseases between the regions of Eastern and Western Slovakia was confirmed in 7 questions $8-10 \& 12-15$ (it was not confirmed only in 2 theoretical Questions $7 \& 11$ ). Health awareness is statistically significantly higher in a selected sample of respondents from Western Slovakia.

In their study, Sultan et al. (7) attempted to use a psychometric tool to assess the level of knowledge and awareness of Hepatitis $\mathrm{C}$ infection in HCV (Hepatitis $\mathrm{C}$ ) positive patients. This study revealed that proper knowledge of $\mathrm{HCV}$ transmission patterns in $\mathrm{HCV}$-infected patients was unsatisfactory in most participants. The proportion of correct answers to knowledge questions among $\mathrm{HCV}$-infected patients varied considerably, ranging from $19.5 \%$ to $87.5 \%$, with various gaps in knowledge and misunderstandings about such transmission methods as; vertical transmission and hand-shaking transmission; kissing; working with someone who has HCV.

In verifying the 2 nd hypothesis, we assumed that respondents with higher education go to preventive check-ups more regularly than people with lower education. We verified this hypothesis with Question 21 from the questionnaire. We also added testing Questions 17, 18, 19 to see if respondents were monitoring their health status. From the total number of 400 respondents (100\%) we see that $71.8 \%$ go to preventive check-ups regularly; $28.3 \%$ do not go to regular check-ups. Preventive check-ups are regularly attended by: 19 respondents with elementary education; 47 respondents with secondary school without a school leaving examination, 125 with secondary school with a school leaving examination; 96 respondents with a university degree. Furthermore, we can see that preventive checkups are not attended by: 2 respondents with elementary education; 27 respondents with secondary school without a school leaving examination; 48 with secondary school with a school leaving examination; 36 with a university degree. Differences depending on education are statistically significant $(p=0.013)$.
Conclusion: Hypothesis 2 was confirmed only in Question 21 which concerned participation in preventive examinations; participation was significantly higher in respondents with higher education $(p=0.013)$. However, the hypothesis has not been confirmed in health status monitoring issues $(16,17,18)$. Differences in care for one's health do not depend on education $(\mathrm{p}>0.05)$.

In verifying Hypothesis 3, we assumed that in Eastern Slovakia there is a lower health awareness of the population regarding healthy diet than in Western Slovak Republic. Current eating habits can be defined as regular intake of foods with a high energy value and at the same time with a low nutritional value, while the intake of highly nutritious foods (fruits, vegetables, legumes) is suppressed (8). We verified this hypothesis with Questions 22, 23, 25, 26, 27.

Conclusion: Hypothesis 3 was confirmed in only 3 questions $22,26,27$. Nevertheless, we state that the health awareness of a healthy diet is higher in the regions of Western Slovakia.

Most European member states do not focus on food security and sustainability, e.g. local fruits and vegetables are rarely recommended. The closer the food is grown, the shorter its storage, transport and ultimately the loss of nutrients. This is especially true for vegetables and fruits. The average fruit and vegetable intake in Europe is too low. This can only be improved if the availability and access to vegetables and fruit is improved. Recommendations to consume a varied diet especially of plant origin are contained in most national dietary recommendations. It is important to eat the widest possible range of foods in order to increase the variety of nutrients consumed. Plant-based foods contain many biologically active ingredients or metabolites with a strong protective role against diseases, in particular non-communicable diseases (8).

Scientific studies focused on various populations, among them especially the so-called Seven Countries Study, have shown that the Mediterranean Diet has a positive effect on health and reduces mortality from a variety of causes, in particular mortality from cardiovascular diseases and cancer (9). It also reduces the incidence of neurodegenerative diseases, including Parkinson's and Alzheimer's. The Mediterranean Diet 
plays a very important role in the prevention of metabolic syndrome - a disease with high cardiovascular risk, which is characterized by a set of risk factors and symptoms occurring in the patient at the same time (obesity, high cholesterol, high blood pressure, impaired glucose tolerance) (5). In order to improve the health of the population, it is necessary to pay great attention to the education of the population about healthy nutrition by all, public health authorities, medicine and nursing.

\section{Conclusion}

A varied diet containing healthy and tasty foods from around the world is generally considered to be a natural and sensible solution in the nutrition of every healthy individual (10). A Mediterranean Diet with a frequent and rich proportion of sea fish, seafood, whole grains, olive oil, fruits and vegetables could be an ideal solution for us. There are no foods that can "regenerate" or "rejuvenate" a human body. However, proper nutrition and a healthy lifestyle will help to maintain vitality even in old age and reduce the risk of serious diseases such as cancer, heart and vascular diseases, diabetes, obesity or osteoporosis. Even if someone suffers from one of these diseases, it is usually possible to reduce its negative impact on health by making the right nutritional decision (11).

It is important to intensify the cooperation between public health professionals and GPs, internists, hepatologists, gastroenterologists and others involved, which would help to address a major societal problem and improve citizens' health (12). At the same time, it is necessary to increase the education of clients about chronic liver diseases; diseases of civilization as well as about healthy eating not only through specialist clinics; but especially through the Health advisory which are located at the Public Health Authorities. It is essential to support the development and funding of well-managed national information campaigns to raise awareness of chronic diseases. It is important to promote the principles of quality and effective primary and secondary prevention, especially in order to protect and restore the health of patients with liver diseases. Close cooperation with GPs is a basic precondition for the successful solving of this issue (13).

\section{References}

1. KIMAKOVA T (2020) Overweight and obesity in two groups of university students. p. 217-225. In: Proceedings of the Days of Practical Obesitology and Metabolic Syndrome. Bardejov Spa. 1. ed. 2020. p. 442. ISBN 978-83-958245-0-0.

2. BELOVICOVA M, VANSAC P (2019) Selected aspects of medical and social care for long-term ill persons. Krakow: Society of the Slovaks in Poland, 2019, p. 153. ISBN 97883-81111-109-6.

3. BELOVICOVA M, POPOVICOVA M, VANSAC P (2021) The issue of the occurrence of diseases of civilization in social reintegration facilities 1. ed., Bardejov: SSPO, 2021, p. 245. ISBN:978-80-971460-8-5.

4. BELOVICOVA M, ADAMCOVA-SELCANOVA S (2017) Obesity and liver diseases. In: Proceedings of the Days of Practical Obesitology and Metabolic Syndrome. Bardejov Spa.1.ed. 2017. p. 294. ISBN 97883-7520-221-2.

5. BABECKA J (2020) The impact of the Mediterranean diet on the health of the individual.p. 110-17. In: Proceedings of the Days of Practical Obesitology and Metabolic Syndrome. Bardejov Spa. 1. ed. 2020. p. 442. ISBN 978-83-958245-0-0.

6. KIMAKOVA T (2018) Monitoring of selected lifestyle factors of university students. Kosice: Pavol Jozef Safarik University in Kosice, 2018. p. 111. ISBN 978-80-9714606-1.

7. SULTAN NY et al. (2018) Assessing the level of knowledge and available sources of information about hepatitis $C$ infection among HCV-infected Egyptians. In: BMC Public Health 18, 2018, p. 747.

8. PLSKOVA A, KACMARIKOVA M, OCHABA R (2020). Current eating habits conditioning overweight and obesity in Slovakia. pp. 326-341. In: Proceedings of the Days of Practical Obesitology and Metabolic Syndrome. Bardejov Spa. 1. ed. 2020. p. 442. ISBN 978-83-958245-0-0.

9. MIRMIRAN P et al. (2015) Longitudinal Study of Adherence to the Mediterranean Dietary Pattern and Metabolic Syndrome in a Non-Mediterranean Population. In Int. J. Endocrinol Metab. 2015; 13(3): e26128. 
10. POPOVICOVA M, KOVACSOVA B (2016) The importance of fasting blood glucose and postprandial blood glucose in the prevention of diabetic retinopathy. In Florence. Prague: Ambit Media, 2016, vol. 7, no. 11, pp. 18-22. ISSN 1801-464X.

11. WISE J (2015) Reduced breastcancer risk seen with Mediterranean diet and added olive oil. In BMJ. 2015; p 351: h4911.

12. BALAZOVA I (2020) Chronic viral liver disease - a challenge for public health. Bardejov: SSPO, 2020, p. 147. ISBN 978-80971460-7-8.

13. MARTINSKY D (2011) Hepatitis - current options for a general practitioner. In Medical practice: professional supplement for outpatient care physicians. ISSN 1336-8109, 2011, vol. 6, no. 6, pp. 6-7. 